\section{P26 Let's Not Sugar Coat It! Canada's Sugary Drinks Reduction Campaign}

Jennifer Giurgevich, MScFN, RD,

jennifer.giurgevich@canada.ca, Health Canada, 100

Eglantine Driveway, Ottawa, Ontario K1A 0K9;

Jennifer McCrea, RD; Katie Faloon-Drew, MSc;

Christina Tucker, MPH, RD; Carri Cossais, BA

Objective: Canada's Sugary Drinks Reduction Campaign aims to increase the awareness, knowledge and understanding among parents of pre-teens and teens about the "why" and "how" of replacing sugary drinks with water. Target Audience: Parents of pre-teens and teens; health professionals and Canadians.

Theory, Prior Research, Rationale: Pre-teens and teens aged 9-18 years have the highest percent contribution to sugars in their diets from sugary drinks, followed by adults 19-50 years of age. The consumption of sugars, specifically from sugary drinks, can lead to an increased risk of obesity, type 2 diabetes, and dental caries. Research findings also show that the parents of pre-teens and teens are the key influencers for their sugary drink consumption and the majority of sugary drinks are consumed in the evening and in the home.

Description: The Sugary Drinks Reduction Campaign will use the following strategic approach: educate and empower leverages video assets to drive awareness, educate and underline target's control over the behaviour; solution support leverages tactics to remind and support target with ideas and solutions to overcome perceived barriers; and stay "top of mind" by reaching target audience with messaging at key times to secure intention (at home or at purchase decision).

Evaluation: The performance measurements will explore the relevance, design, planning, implementation and effectiveness of the campaign, including the collaboration between Health Canada and stakeholders. Aspects of this evaluation will be incorporated into the evaluation of Canada's Healthy Eating Strategy.

Conclusions and Implications: Canada's Sugary Drinks Reduction Campaign is one of many initiatives within Canada's Healthy Eating Strategy that supports the government of Canada's commitment to making the healthy choice the easy choice.

Funding: None.

\section{P27 Parental Ethnotheories About Healthy Eating: Exploring the Developmental Niche of Preschoolers}

Deepa Srivastava,PhD, dsr@ucdavis.edu, University of California Cooperative Extension, 4437-B S Laspina Street, Tulare, CA 93274; Julia Torquati, PhD, University of Nebraska-Lincoln; Maria Rosario T. de Guzman, PhD; Dipti Dev, PhD

Background (Background, Rationale, Prior Research, and/or Theory): Parents' structure and participate in daily activities with their children in ways that resonate with their cultural beliefs known as parental ethnotheories. Healthy eating is a daily activity that can be shaped by parental ethnotheories.

Objective: To understand parental ethnotheories (i.e. cultural beliefs) that support preschool-age (3-5 years) children's healthy eating guided by the three components of the developmental niche theoretical framework: physical and social settings of everyday routines, customs of childrearing practices, and parental ethnotheories.

Study Design, Setting, Participants, Intervention: Utilizing hermeneutic phenomenology design, one-onone interviews were conducted with 20 primary caregivers of preschool-age children until data saturation. Participants were selected using purposive sampling.

Outcome Measures and Analysis: Data was analyzed using MaxQDA to develop codes and themes about parental ethnotheories that support preschool-age children's healthy eating.

Results: Three overarching themes and related subthemes emerged. Theme 1 was parental ethnotheories about the meaning of healthy eating included subthemes around participants' definitions of healthy eating, motivations to support children's healthy eating, and sources of knowledge about healthy eating. Theme 2 was parental ethnotheories that supported organization of children's physical and social settings included a structured mealtime routine and participants' food socialization strategies. Theme 3 was parental ethnotheories that supported children's learning about healthy eating included parentchild communication and engagement in age appropriate food activities such as meal preparation, visiting farmer's market, grocery shopping, gardening, cooking, and baking. Conclusions and Implications: Developmental niche of preschool-age children constitutes an interactive system (i.e. physical and social settings, childrearing practices, and parental ethnotheories) in which ethnotheories serve as guides to parenting practices where healthy eating messages are conveyed and practiced. Primary caregivers' knowledge/skills about healthy foods and positive feeding practices are important. Findings make an important contribution to the scant literature on parental ethnotheories that support preschool-age children's healthy eating, thus, presenting a unique qualitative contribution to the field of parenting/cultural food environment research.

Funding: USDA-AFRI.

\section{P28 Relationships Between Paternal Parenting Practices and Eating, Physical Activity, and Screen Time Behaviors of Latino Youth}

Youjie Zhang, MS, University of Minnesota; Alejandro Peralta Reyes, MPH, RD;

Patricia Arellano Brazys, BS, RD; Marla Reicks, PhD, RD, mreicks@umn.edu, University of Minnesota, 1334 Eckles Avenue, St. Paul, MN 55108

Background (Background, Rationale, Prior Research, and/or Theory): Latino fathers are generally considered the head of the family with a central role in

Continued on page S21 